\title{
Description of a widely distributed but overlooked amphipod species in the European Alps
}

\author{
ROMAN ALTHER ${ }^{1,2 *}$, CENE FIŠER ${ }^{3}$ and FLORIAN ALTERMATT ${ }^{1,2}$ \\ ${ }^{1}$ Department of Aquatic Ecology, Eawag, Swiss Federal Institute of Aquatic Science and Technology, \\ CH-8600 Dübendorf, Switzerland \\ ${ }^{2}$ Department of Evolutionary Biology and Environmental Studies, University of Zurich, CH-8057 \\ Zürich, Switzerland \\ ${ }^{3}$ Department of Biology, Biotechnical Faculty, University of Ljubljana, SI-1001 Ljubljana, Slovenia
}

Received 11 December 2015; revised 18 April 2016; accepted for publication 17 May 2016

\begin{abstract}
Amphipods are keystone species in many freshwater ecosystems. Understanding their distribution and diversity is crucial to ensure and preserve freshwater ecosystem functioning, particularly in the northern hemisphere. For the European Alps information on amphipods has been relatively limited until recently. We describe a new, widely distributed amphipod species, Gammarus alpinus sp. nov., found across the Alps and analyse its distribution, biogeography as well as genetic and morphological differentiation. Until now, this species has been reported as Gammarus lacustris. Based on genetic and morphometric measurements, we show that G. alpinus is highly divergent from $G$. lacustris. The latter has a circumpolar distribution, but may be absent from the Alps. The observed occurrence pattern of $G$. alpinus might be explained by a Pliocene range expansion and vicariance due to climate warming following the Quaternary glaciation. Historical drainage divides suggest a single recolonization route from a distinct southern refugium. While G. lacustris is widely distributed and not endangered at a global scale, G. alpinus is endemic to the Alps and its habitat is negatively affected by eutrophication, non-native species and possibly climate change.
\end{abstract}

(C) 2016 The Linnean Society of London, Zoological Journal of the Linnean Society, 2016 doi: 10.1111/zoj.12477

ADDITIONAL KEYWORDS: alpinus - Amphipoda - biogeography - COI - endemic - Gammarus lacustris - morphology.

\section{INTRODUCTION}

Freshwater environments only cover about $2 \%$ of the Earth's surface, but nearly comprise equal species richness as marine environments, which cover $\sim 70 \%$ of the Earth's surface (Wiens, 2015). Alarmingly, the high diversity in freshwater systems is severely threatened, as these ecosystems are especially sensitive to environmental changes (Vörösmarty et al., 2010). Thus, from a conservation perspective, the identification of diversity hotspots as well as regions of high endemism is needed. Surprisingly for many major groups of invertebrates, solid databases on

*Corresponding author. E-mail: roman.alther@eawag.ch

[Version of Record, published online 06 September 2016.] their occurrences as well as possible conservation status are lacking (e.g. Revenga et al., 2005).

For freshwater ecosystems, the European Alps are a biogeographically interesting region. Different major European drainage systems originate in the Alps, such as the rivers Rhine, Rhone, Po and Danube. The European Alps harbour many endemic species (Nagy et al., 2012), which suggests a high priority for conservation of alpine biodiversity (Fontaine et al., 2007; Dirnböck, Essl \& Rabitsch, 2011; Jacobsen et al., 2012). The need for such conservation measures is corroborated by the fact that the European Alps are, compared to other mountainous regions, densely populated, and heavily affected by anthropogenic changes, such as habitat alteration and climate warming. 
The current species distributions of freshwater organisms in Europe are strongly shaped by the Pleistocene ice ages as a major palaeoclimatic phenomenon (Hewitt, 1999; Foulquier et al., 2008). Refugia in ice-free regions acted as 'safe harbours' during glacials, especially for temperate-adapted species (e.g. Stewart et al., 2010). After deglaciation and recolonization this can lead to divergence of species which often remains cryptic due to the geologically short time scale (e.g. Williams, Ormerod \& Bruford, 2006). This phenomenon is prevalent in amphipods and isopods throughout Europe (Müller, Partsch \& Link, 2000; Vainio \& Väinölä, 2003; Fišer et al., 2015; Sworobowicz et al., 2015) but their species status often remains unclear. The conjuncture of a highly variable morphology within species (Karaman \& Pinkster, 1977a) combined with cryptic diversity between species resulted in a long lasting debate about the phylogeny and taxonomy in the genus Gammarus (Fabricius 1775). Even on the family level (Gammaridae) many uncertainties remain (see Hou \& Sket, 2016 for an overview).

Amphipods belong to the most important freshwater organisms with respect to biomass as well as ecosystem processes in many freshwater systems (Holsinger, 1976; Väinölä et al., 2008). They have an important ecosystem function in aquatic foodwebs, linking terrestrial detritus input to higher trophic organisms, such as fish (Rogers, Covich \& Thorp, 2010). Furthermore, they are often used as indicator taxa for ecological monitoring (e.g. Stucki, 2010) and ecotoxicological tests (Gerhardt, 2011). Surprisingly, existing knowledge about amphipods in the European Alps is diametrically opposed to their ecological importance. For example, while there are individual species identification keys for Italy (Karaman, 1993), Germany (Eggers \& Martens, 2001) or a genus identification key for France (Tachet et al., 2010), an identification key integrating all alpine drainage areas and covering the whole alpine range is lacking. Furthermore, for some countries, first checklists of amphipods have been only recently published (e.g. Switzerland: Altermatt et al., 2014) or are not up to date (e.g. Austria: Vornatscher, 1965). Through the recent use of genetic tools it became clear that many amphipod species in mountainious regions form highly diverse species groups, and that the level of undescribed species is relatively high, for example within the genus Gammarus (Müller, 2000; Westram et al., 2011; Mamos et al., 2014, 2016; Weiss et al., 2014; Katouzian et al., 2016). Recent colonizations by invasive species add to the complexity of the status but also change within amphipod communities.

A prominent member of the family Gammaridae is the species Gammarus lacustris (Sars 1863). It has an exceptionally wide, circumboreal distribution that can maintain gene flow across three continents (MacDonald, Yampolsky \& Duffy, 2005; Hou et al., 2011; Hou, Sket \& Li, 2014; but see Katouzian et al., 2016). This stands in contrast to most freshwater amphipods having small, endemic distributions (Väinölä et al., 2008). In Europe, G. lacustris has been reported from northern Germany, Denmark and Fennoscandia in many publications (Supporting Information, Table S1) and is commonly reported to be present in the Alps and prealpine lakes (e.g. Hynes, 1957; Meyran \& Taberlet, 1998; Altermatt, Alther \& Mächler, 2016; Supporting Information, Table S1). Past studies analysing the global distribution of G. lacustris, however, almost completely overlooked populations from the European Alps, and up to now there is no conclusive overview on its distribution as well as taxonomic identity throughout the European Alps in general, and for some countries in particular there are only few historical reports that date back to a pre-molecular biology era (Schellenberg, 1934; Hynes, 1957). Given its highly disjunct occurrence in the Alps, the species status and relationship of alpine populations to all other populations of G. lacustris worldwide potentially needs revision (see also Katouzian et al., 2016).

Here, we studied the distribution and diversity of the G. lacustris complex in alpine lakes. Thereby, we identified a clear genetic and morphological distinction between circumpolar G. lacustris and its alpine populations. Given that alpine populations are genetically and morphologically differentiated and geographically stable isolated from all other populations we raise the alpine group to the species level, describing it as Gammarus alpinus sp. nov. We present the first overview of its distribution throughout the Alps and give remarks on its ecological and morphological characteristics. This new gammarid species, probably endemic to the Alps, poses some major implications for the conservation of alpine lakes and the introduction of amphipods or fish in these lakes.

\section{MATERIAL AND METHODS}

\section{DATA SOURCE AND FIELDWORK}

We used a combination of literature research and our own fieldwork to get a comprehensive understanding of the occurrence of the G. lacustris complex in the European Alps and prealpine areas. First, we conducted a Web of Science query with the keywords "gammarus' and" lacustris' (also "g.' and" lacustris'). In addition, we performed the same search within the ETH internal library search (http://www.li brary.ethz.ch/en/) and Eawag internal library search (http://www.lib4ri.ch/), which includes additional unpublished records and reports specifically for 
Switzerland, and followed up references given in the studies read. We in total screened 139 publications and reports (107 publications in Supporting Information, Table S1), from which we extracted all existing information on occurrence and (when available) known absences of the G. lacustris complex in alpine and prealpine freshwater habitats. Given that there was a lack of literature records especially from the Swiss Alps, we additionally queried the collections of 18 major natural history museums of Switzerland (among others, the Natural History Museum of Basel, Lausanne and Zurich), as well as the Natural History Museum in Berlin with a large amphipod collection for records of $G$. lacustris.

We complemented these data with a field sampling campaign, covering in total 102 lakes in France, Switzerland, Italy and Austria (Supporting Information, Table S2), which were chosen to be suitable for the G. lacustris complex based on available information regarding lake size, elevation and accessibility. The sampled lakes are located between 258 and $2381 \mathrm{~m}$ a.s.l. At each lake we collected amphipods with the kicknet technique. We sampled the littoral zone (max. depth sampled: $1.5 \mathrm{~m}$ ) until reaching a threshold of at least 20 sampled individuals, but at least 15 min per site or $60-120$ min per lake. If lake size and habitat structure indicated the absence of amphipods we nevertheless sampled at least $30 \mathrm{~min}$. In all lakes where we found the G. lacustris complex, individuals were found within $45 \mathrm{~min}$, in most lakes within 5-10 min of search efforts. Sampled individuals were pre-sorted in the field and preserved in molecular-grade ethanol (80\%) for subsequent identification. Individuals were identified to species level according to Karaman (1993) and Eggers \& Martens (2001) using a Nikon SMZ1500 (Nikon AG, Egg, Switzerland) or Leica M205C (Leica Microsystems, Heerbrugg, Switzerland) stereo microscope. For comparative purposes, ten additional specimens from Fennoscandia (Finland and Norway) were kindly provided by Dr Risto Väinölä (University of Helsinki).

\section{MOLECUlAR ANALYSIS}

DNA was extracted from a total of 86 individuals (Supporting Information, Table S3; 76 alpine and ten Fennoscandian specimens). We dissected tissue from left pereopods 5-7, and extracted DNA using the DNeasy Blood \& Tissue kit (Qiagen AG, Hombrechtikon, Switzerland). We applied the spin column protocol for animal tissue as provided by the manufacturer's handbook and incubated the proteinase reaction overnight. We then added $5 \mu \mathrm{L}$ RNase A $\left(10 \mathrm{mg} \mathrm{mL}^{-1}\right)$ and incubated the reactions at $37^{\circ} \mathrm{C}$ for $30 \mathrm{~min}$ to yield better results as suggested by our preliminary tests. For small individuals we also used pereopods $3-4$, to ensure enough sample material. The final elution step was performed twice, using only $50 \mu \mathrm{L}$ of $\mathrm{AE}$ buffer and eluting into different microcentrifuge tubes. PCR was conducted using the second elution of the DNA extraction. The final reaction volume of $15 \mu \mathrm{L}$ resulted from $2.5 \mu \mathrm{L} \mathrm{H}_{2} \mathrm{O}, 1 \times$ Qiagen Multiplex Mastermix $(7.5 \mu \mathrm{L}), 0.5 \times$ Q-Solution $(1.5 \mu \mathrm{L}), 0.5 \mu \mathrm{M}$ of each primer $(2 \times 0.75 \mu \mathrm{L})$ and $2 \mu \mathrm{L}$ DNA template from the second elution from the previous extraction. Primers used were 'LCO1490' and 'HCO2198' (Folmer et al., 1994) for the mitochondrial COI (Cytochrome c oxidase subunit I) gene fragment. Primers for the mitochondrial $12 \mathrm{~S}$ rRNA gene were $5^{\prime}$ GCCAGCAGCCGCGGTTA- $3^{\prime}$ and $5^{\prime}$-CCTACTTTGTTACGACTTAT-3' (Trontelj \& Utevsky, 2005). The PCRs were conducted on a Biometra TProfessional/ Standard thermal cycler (Biometra $\mathrm{GmbH}$, Göttingen, Germany). For COI amplification we used the following protocol: initial denaturation of $15 \mathrm{~min}$ at $95{ }^{\circ} \mathrm{C}$ followed by 35 cycles of $30 \mathrm{~min}$ at $94{ }^{\circ} \mathrm{C}$, $90 \mathrm{~min}$ at $40^{\circ} \mathrm{C}$ and $60 \mathrm{~min}$ at $72^{\circ} \mathrm{C}$. A final annealing time of $10 \mathrm{~min}$ at $72{ }^{\circ} \mathrm{C}$ was applied before the steady state at $4{ }^{\circ} \mathrm{C}$. For $12 \mathrm{~S}$ amplification we used the following protocol: initial denaturation of $3 \mathrm{~min}$ at $94{ }^{\circ} \mathrm{C}$ followed by 50 cycles of $30 \mathrm{~min}$ at $94{ }^{\circ} \mathrm{C}$, $60 \mathrm{~min}$ at $45{ }^{\circ} \mathrm{C}$ and $60 \mathrm{~min}$ at $72^{\circ} \mathrm{C}$. A final annealing time of $10 \mathrm{~min}$ at $72{ }^{\circ} \mathrm{C}$ was applied before the steady state at $4{ }^{\circ} \mathrm{C}$. After checking the resulting fragments on gel pictures, all positive PCR products were purified with Exo I nuclease (Exo I) and shrimp alkaline phosphatase (SAP) (Thermo Fisher Scientific, Waltham, Massachusetts, USA) to remove primers and dNTPs. The master mix consisted of 1.6 $\mathrm{U} \mu \mathrm{L}^{-1}$ Exo I and $0.15 \mathrm{U}_{\mu} \mathrm{L}^{-1} \mathrm{SAP}$ in a total volume of $1.1 \mu \mathrm{L}$ per reaction. We then added the mix to $7.5 \mu \mathrm{L}$ of the PCR product and incubated it at $37^{\circ} \mathrm{C}$ for $15 \mathrm{~min}$, followed by $15 \mathrm{~min}$ at $80^{\circ} \mathrm{C}$. Cycle sequencing was performed using BigDye Terminator v3.1 (Thermo Fisher Scientific). The same sequences as amplification primers and the same thermal cycler were used. Cycling conditions were according to the following protocol for both markers: initial denaturation of $1 \mathrm{~min}$ at $96^{\circ} \mathrm{C}$ followed by 25 cycles of $10 \mathrm{~min}$ at $96{ }^{\circ} \mathrm{C}, 5 \mathrm{~min}$ at $50{ }^{\circ} \mathrm{C}$ and $4 \mathrm{~min}$ at $60^{\circ} \mathrm{C}$. The final steady state was at $10^{\circ} \mathrm{C}$. DNA precipitation of cycle sequencing products was done using an EDTA-ethanol precipitation protocol. HiDi formamide was added to the precipitated cycle sequencing products to resuspend them. Subsequently the products were sequenced on an Applied Biosystems 3130xl Genetic Analyzer at the Genomic Diversity Centre of ETH Zurich.

Raw sequence reads were verified and aligned using Sequencher version 5.3 sequence analysis 
software (Gene Codes Corp., Ann Arbor, Michigan, USA). COI sequences were only included into further analysis when longer than $500 \mathrm{bp}$ with sufficient sequence read quality (at least $65 \%$ when combined, but mostly above 95\%) and containing no stop codons or pseudogenes. The same holds for the $12 \mathrm{~S}$ data, where the minimum length was $450 \mathrm{bp}$ and sequence read quality usually above $90 \%$. COI sequences were aligned to GenBank nucleotide sequences using the online Standard Nucleotide BLAST (blastn: https:// blast.ncbi.nlm.nih.gov/Blast.cgi?PROGRAM=blastn\&PAGE_TYPE=BlastSearch\&LINK_LOC=blasthome) application and checked for taxonomic consistency with own identification. The subsequent sequence alignment of 82 newly generated COI sequences (Supporting Information, Table S3; 74 alpine and eight Fennoscandian specimens), combined with 16 previously generated sequences from an earlier project on Lake Constance (Altermatt et al., 2016) and 23 publicly available COI sequences from G. lacustris (accession numbers in Supporting Information, Table S4) was done in MEGA6 (Tamura et al., 2013) using the implemented ClustalW algorithm (Larkin et al., 2007). This resulted in $121 \mathrm{COI}$ sequences for the G. lacustris complex (91 alpine, 30 from Holarctic). An additional 77 outgroup sequences from other Gammarus species and amphipod genera were generated in our lab following the described protocols. In detail, we compiled ten sequences from Crangonyx pseudogracilis (Bousfield 1958), 22 sequences of Gammarus roeseli (Gervais 1835), 21 sequences of Gammarus fossarum (Koch 1836) and 24 sequences of Gammarus pulex (Linneaus 1758). For 12S there are currently no sequences available on GenBank and the alignment for subsequent analysis is based on our 83 newly generated sequences solely (Supporting Information, Table S3; 73 alpine and ten Fennoscandian specimens).

We tested the monophyly of the entire G. lacustris complex using a maximum-likelihood (ML) analysis. The phylogeny for COI based on ML was inferred in MEGA6 using standard settings (K2P, GTR $+\mathrm{G}+\mathrm{I}$, 100 bootstraps). The substitution model was selected among 88 possible models using jModeltest 2.1.7 (Guindon \& Gascuel, 2003; Darriba et al., 2012) based on $\log \mathrm{L}$. The underlying data were 198 untrimmed COI sequences (121 sequences of the G. lacustris complex and 77 outgroup sequences), of which MEGA6 used 519 positions to reconstruct the phylogenetic tree (data not shown). The phylogenetic tree based on the $12 \mathrm{~S}$ alignment consisted of 83 sequences and was computed analogous to compare the tree topology consistency with COI-derived results (data not shown).

As we noted a deep divergence between alpine and non-alpine G. lacustris, we explored the relationship between the two clades in more detail and also estimated the age of the split by reconstructing a rooted time tree with a Bayesian approach in BEAST 2.3.0 (Bouckaert et al., 2014). The phylogenetic tree for COI was inferred based on all 121 untrimmed sequences (see Wiens \& Moen, 2008) without outgroup species (Drummond \& Bouckaert, 2015). The data were partitioned according to codon position (Brandley et al., 2011) previous to Bayesian analysis, using the same model for all partitions. Preliminary, different evolutionary models for COI sequence data were compared by Effective Sample Size (ESS) values, log-traces and ultimately Akaike's information criterion through Markov chain Monte Carlo (AICM) values (Baele et al., 2012). ESS values $>200$ were interpreted as adequate for further analysis (Drummond \& Bouckaert, 2015). Tested site substitution models were HKY and GTR with gamma distributed rate variation among sites $(+\mathrm{G})$ and different gamma category counts. Furthermore, the presence of invariant sites $(+\mathrm{I})$ was tested according to ESS and AICM. Frequencies of substitutions were taken from empirical values, whereas rates were estimated in BEAST and compared to equal rates. Subsequently, we selected the molecular clock model by comparing a strict molecular clock to a relaxed clock and a random local clock (Drummond \& Suchard, 2010) to select the best model for inferring the chronogram. As clock rate we implemented a mean value of 0.0115 , previously reported from other gammarid species (Lefébure et al., 2007; Hou \& Li, 2010; Copilaş-Ciocianu \& Petrusek, 2015). As population function for the tree prior, we employed the simpler Yule model and compared it to a coalescent constant population model, a birth-death model, and a coalescent exponential population model. The final Bayesian inferred (BI) phylogeny for COI was based on HKY as site model, a relaxed log-normal molecular clock model and a coalescent constant population model prior. The length of the Monte Carlo Markov chain (MCMC) was set to 10000000 with a pre burn-in of 100000 steps and trees stored every 10000 steps. The trace logs from the MCMC runs were inspected in Tracer 1.6. Subsequently, six MCMC runs were combined in LogCombiner 2.3.0 and resampled every 10000 steps. Combined tree logs were annotated in TreeAnnotator 2.3.0 by the maximum sum of clade credibilities with a burn-in of 10\%, visualized in TreeGraph 2.7.1 (Stöver \& Müller, 2010) and edited in Adobe Illustrator CS6 (Adobe Systems, Inc., San Jose, California, USA). Due to the limited geographical coverage of $12 \mathrm{~S}$ sequences we did not compute a time tree in BEAST.

Finally we tested whether the alpine populations deserve species status. Species delimitation based on the barcoding gap was inferred from pairwise inter- 
and intraspecific distances for $\mathrm{COI}$ and $12 \mathrm{~S}$, calculated in MEGA6 as nucleotide substitutions corrected with the Kimura two-parameter model (Kimura, 1980), again with transitions and tranversions and Gamma distributed rates among sites (parameter $=1$ ). The respective histograms were plotted in $R$ version 3.1.3 ( $\mathrm{R}$ Core Team, 2015).

Species delimitation based on COI data by a Poisson Tree Processes (PTP) model (Zhang et al., 2013) was conducted using the server-based Bayesian implementation bPTP as provided on http://species.hits.org/. Here, the data basis was a rooted tree generated in MEGA6 inferred from ML (standard settings: $\mathrm{K} 2 \mathrm{P}, \mathrm{GTR}+\mathrm{G}+\mathrm{I}$ ) and based on all sequences available for the G. lacustris complex (total: 121) and 24 newly generated G. pulex sequences as outgroup (same data as for the COI ML-phylogeny but with only one outgroup species). The bPTP analysis ran for 100000 MCMC generations, 100 thinning runs and a burn-in of 0.1 .

The COI haplotype network was constructed in popART (Leigh, Bryant \& Steel, 2015) as a medianjoining network (Bandelt, Forster \& Röhl, 1999) and is based on the previously used 121 sequences of the G. lacustris complex.

$\mathrm{COI}$ and $12 \mathrm{~S}$ sequences were uploaded to the Barcode of Life Database (BOLD, http://v3.boldsystems. org/), automatically given barcode status after approval and assigned to separate BINs (Barcode Index Numbers) by implemented sequence cluster algorithms. Pairwise distances and geographical distribution can directly be viewed online.

\section{MORPHOMETRIC ANALYSIS}

We dissected 86 adult individuals from 20 locations (same individuals as for molecular analysis), and prepared microscopic slides with the dissected Antennae 1 and 2, Gnathopods 1 and 2, Pereopods 3-7, the first Pleopod, Uropod 1 and Uropod 3, the Telson and the mouthparts. Body parts were generally taken from the right lateral side of the body. The removed parts were mounted in Kaiser's glycerol gelatine (Carl Roth GmbH, Arlesheim, Switzerland) as aqueous mounting medium. The mounted parts were covered with a glass slip and the edges sealed with transparent nail polish. Separate photos of all body parts were taken using a Nikon SMZ1500 stereomicroscope and a mounted Canon EOS 5D Mark III under the highest possible magnification. Photos were analysed with ImageJ $1.48 \mathrm{v}$ (Rasband, 2014) using pixel to $\mu \mathrm{m}$ ratios deduced from photos of a microscopic scale bar (Wild Heerbrugg AG, Heerbrugg, Switzerland). For all individuals, 37 morphological characters were recorded (Supporting Information, Table S5). We also noted the sex of the individuals, as not only male individuals were used for analysis. All analysed photos were taken from the lateral side. All length measures were standardized to the mean of the total body length (three measurements). Plots showing the different characters/ lengths against the standard were computed to see putative differences between clades in a visual examination. A principal components analysis (PCA) as ordination method was applied to the raw and logtransformed data (data not shown). Furthermore, analysis on single sex data was conducted. Additionally, the package missMDA (Josse \& Husson, 2012) was used to handle missing values. All analyses were done in $\mathrm{R}$ version 3.1.3 ( $\mathrm{R}$ Core Team, 2015).

\section{ECOLOGICAL ANALYSIS}

The distribution map was generated in ArcMap 10.2.2 (ESRI 2014. ArcGIS Desktop: Release 10). To determine the habitat properties and ecological requirements of the alpine G. lacustris complex we compared whether lakes where individuals were found share common ecological properites. Therefore, we explored the size of lakes and their altitudinal distribution. Based on our experience when collecting samples, we assumed that species live either in rather large lakes at lower elevation or in small higher elevation lakes. The contour plot was generated in $\mathrm{R}$ version 3.1.3 and based on complete cases of ecological data of sampled specimens. Elevation data and lake sizes were used in an individually written script, including the function ' $k$ de2d' from the package MASS (Venables \& Ripley, 2002) and the function 'image' from package graphics (core distribution).

\section{RESULTS}

Our fieldwork and literature research resulted in the first conclusive overview about the occurrence of the G. lacustris complex throughout the Alps, covering France, Italy, Switzerland, Germany, Austria and Slovenia (Fig. 1).

\section{MOLECULAR ANALYSIS}

Alpine and non-alpine specimens of G. lacustris constitute strongly supported monophyletic clades (Fig. 2, Supporting Information, Fig. S1). The alpine populations form a highly distinct and well-supported clade separated from circumpolar G. lacustris populations. Whereas sequences from as far apart as East China (Beijing) and North America (Vancouver Island) cluster together with sequences from Fennoscandia that we generated ourselves, all alpine sequences are clearly separated and form a 


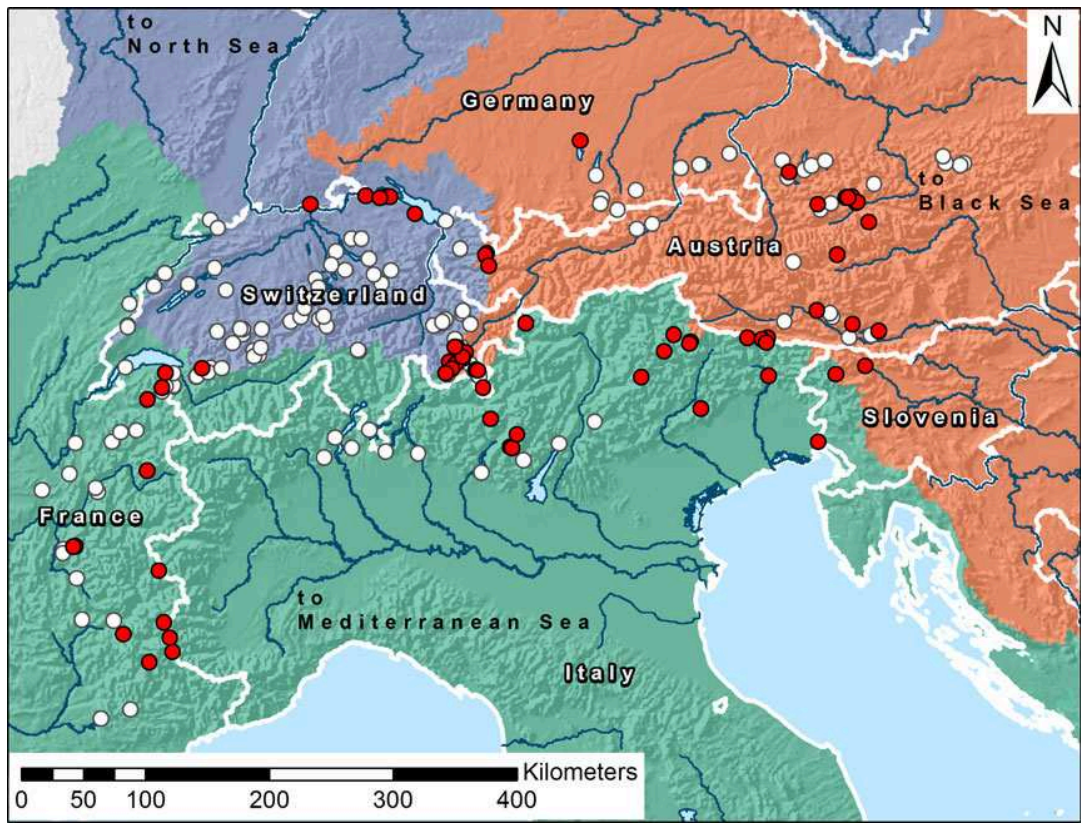

Figure 1. Distribution map of Gammarus alpinus sp. nov. Red circles indicate lakes with populations of G. alpinus, while white circles indicate sampled lakes without $G$. alpinus. The figure summarizes data from the literature and our own sampling. The major alpine drainage areas are given in colour (blue $=$ Rhine/North Sea; orange $=$ Danube/Black Sea; green $=$ Rhone, Po/Mediterranean Sea).

distinct clade. The alpine clade is further divided into two distinct, well-supported subclades (Fig. 2, Supporting Information, Fig. S1). The resulting phylogeny shows a consistent topology regardless of the gene (COI or 12S) and method used (ML or $\mathrm{BI}$ ). Moreover, the general topology of three distinct clades is robust even to different prior parameters in the BI tree. The estimated age of the alpine G. lacustris clade is around $6.7 \mathrm{Myr}$ (95\% interval: 2.3-13.6 Myr).

Furthermore, pairwise distances of the COI sequences (K2P) within and between the initial G. lacustris specimens and the two alpine clades show a clear difference (Fig. 3). The comparisons between the G. lacustris specimens and the alpine specimens show differences greater than $5.2 \%$ (mean $6.5 \%, \pm 0.02 \%)$. By contrast, all 3866 pairwise distances of COI sequences within the three clades (G. lacustris and two alpine ones) are below 5\% [mean $0.65 \%, \pm 0.01 \%$ (SE)]. Exceptions are three comparisons between Asian and North American specimens that are just above 5\% (maximal distance $5.8 \%$ ), but these also reflect the largest geographical distances. Within G. lacustris from Fennoscandia, North America and Asia mean pairwise distance $( \pm \mathrm{SE})$ is $2.2 \%( \pm 0.3 \%)$, compared to $0.8 \%( \pm 0.2 \%)$ within the alpine clades. Data for $12 \mathrm{~S}$ sequences in general show less diversification, but with the same clear cut-off $(5.2 \pm 1.3 \%$ between G. lacustris and alpine specimens, $0.3 \pm 0.1 \%$ within alpine specimens, $0.8 \pm 0.2 \%$ in G. lacustris; Supporting Information, Fig. S2). These findings are consistent with results from $G$. fossarum, in which the threshold for discriminating molecular operational taxonomic units is found to be around 4\% with mate discrimination occurring in sympatric populations (Lagrue et al., 2014; Galipaud et al., 2015).

A haplotype network (Fig. 4) based on COI data corroborates the clustering into two separate species (colours in the figure highlight the origin of the specimens, the circles represent distinct haplotypes). The PTP analysis based on COI suggests delimitation of the G. lacustris complex into two separate species, both by ML and Bayesian analysis of the sequences. PTP support is 0.956 for the initial G. lacustris branch and 0.919 for the new alpine branch (identical values for the Bayesian and ML approaches).

Analysis of the COI barcodes on BOLD resulted in two clear and separated BINs (BOLD:ACH6111 and BOLD:ADB3370) for all alpine specimens, whereas the sequences from the rest of the world were assigned to other, separated BINs. Within the aligned sequences of COI (658 bp) 14 single nucleotide polymorphisms (SNPs) are identified, which are diagnostic for the alpine clade compared to the original G. lacustris. One SNP allows the distinction of all three clades (see Description). 


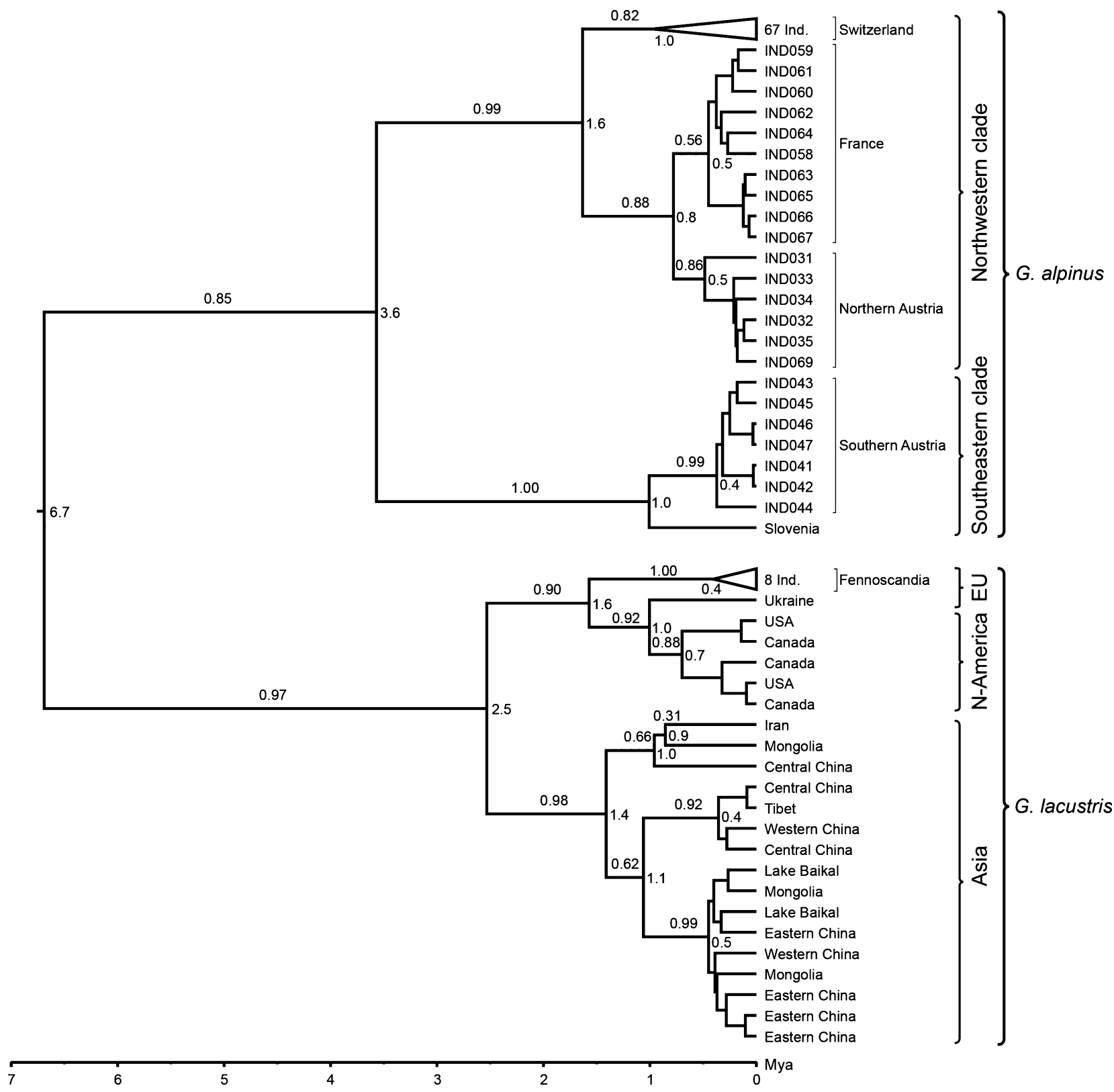

Figure 2. Bayesian-inferred phylogenetic time tree of Gammarus alpinus sp. nov. and Gammarus lacustris. Values above branches (two decimal places) indicate likelihood based on 5406 combined trees. For better readability, individuals from Switzerland and Fennoscandia were also collapsed. Values at nodes (one decimal place) indicate the age of the branch in Myr. Branch lengths indicating divergence time (with a relaxed clock model).

\section{MORPHOMETRIC ANALYSIS}

We find consistent morphological differences of the alpine gammarid clades compared to G. lacustris specimens from Norway and Finland. Most importantly, the alpine specimens almost exclusively bear one group of setae along the anterior margin of the carpopodite of gnathopod 2, while both sexes of G. lacustris always bear two groups of setae (Fig. 5). Further differences are given below in Description of the novel species. The PCA did not reveal a clear difference (data not shown).

Summarizing the molecular data and adding the morphological differences between our alpine samples and the G. lacustris samples from all over the northern hemisphere and given the stable geographical separation, we hereby erect the alpine clade of the previous G. lacustris to the species status by naming it Gammarus alpinus sp. nov. The geographical distances between $G$. lacustris populations being 


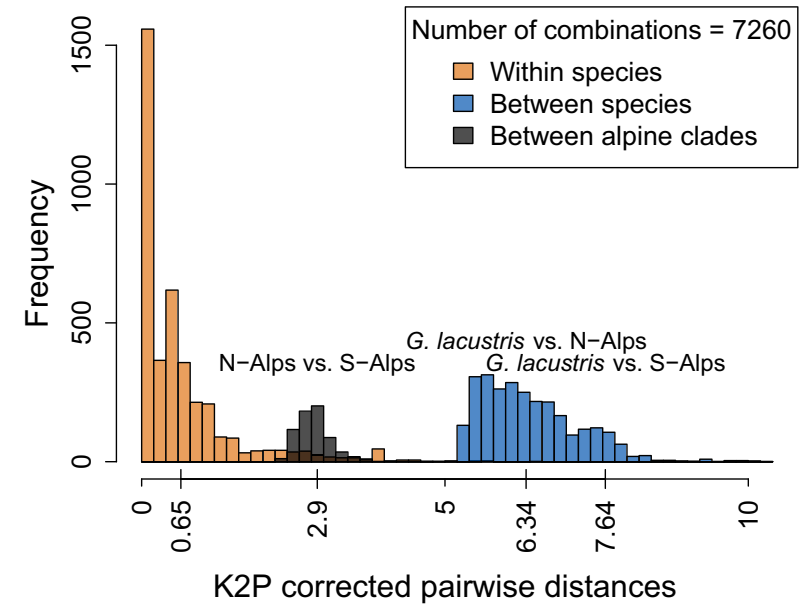

Figure 3. Pairwise differences of COI sequences support species status. Clade divergence as pairwise differences (K2P-corrected) indicates alpine G. alpinus sp. nov. to be different from all other G. lacustris sequences published so far. This diagram supports the species status of the alpine gammarid specimens but does not suggest a further distinction into separate alpine species, as pairwise distances fall into the distances observed worldwide.

larger than those between G. lacustris and G. alpinus, with genetic differences between G. lacustris populations being smaller than genetic differences between G. lacustris and G. alpinus by an order of magnitude, support this nomenclatural act.

\author{
DESCRIPTION OF GAMMARUS ALPINUS SP. NOV. \\ SUBORDER GAMMARIDEA (LATREILLE 1802) \\ FAMILY GAMMARIDAE (LEACH 1813) \\ GAMMARUS ALPINUS SP. NOV. (FIGS 5, 6)
}

References (that now most likely have to be considered G. alpinus sp. nov.)

$1,2,8,12,14-16,19,22,35-38,45,46,49,52-54$, $65,66,72,73,83-86,94,101$ and 102 in Supporting Information (Table S1).

Type locality

Lej da San Murezzan (Lake St. Moritz), Switzerland, $9^{\circ} 50^{\prime} 51.05^{\prime \prime} \mathrm{E}, 46^{\circ} 29^{\prime} 48.02^{\prime \prime} \mathrm{N}$ [WGS84], equivalent to $784901 \mathrm{~m} \mathrm{E}, 152323 \mathrm{~m} \mathrm{~N}$ [CH1903/LV03].

\section{Material examined}

Seventy-seven specimens of G. alpinus in detail (the same were used for molecular analysis), another $\sim 30$ when studying specific characters.

Holotype

The male holotype is deposited in the collection of the Musée de Zoologie, Lausanne, Switzerland

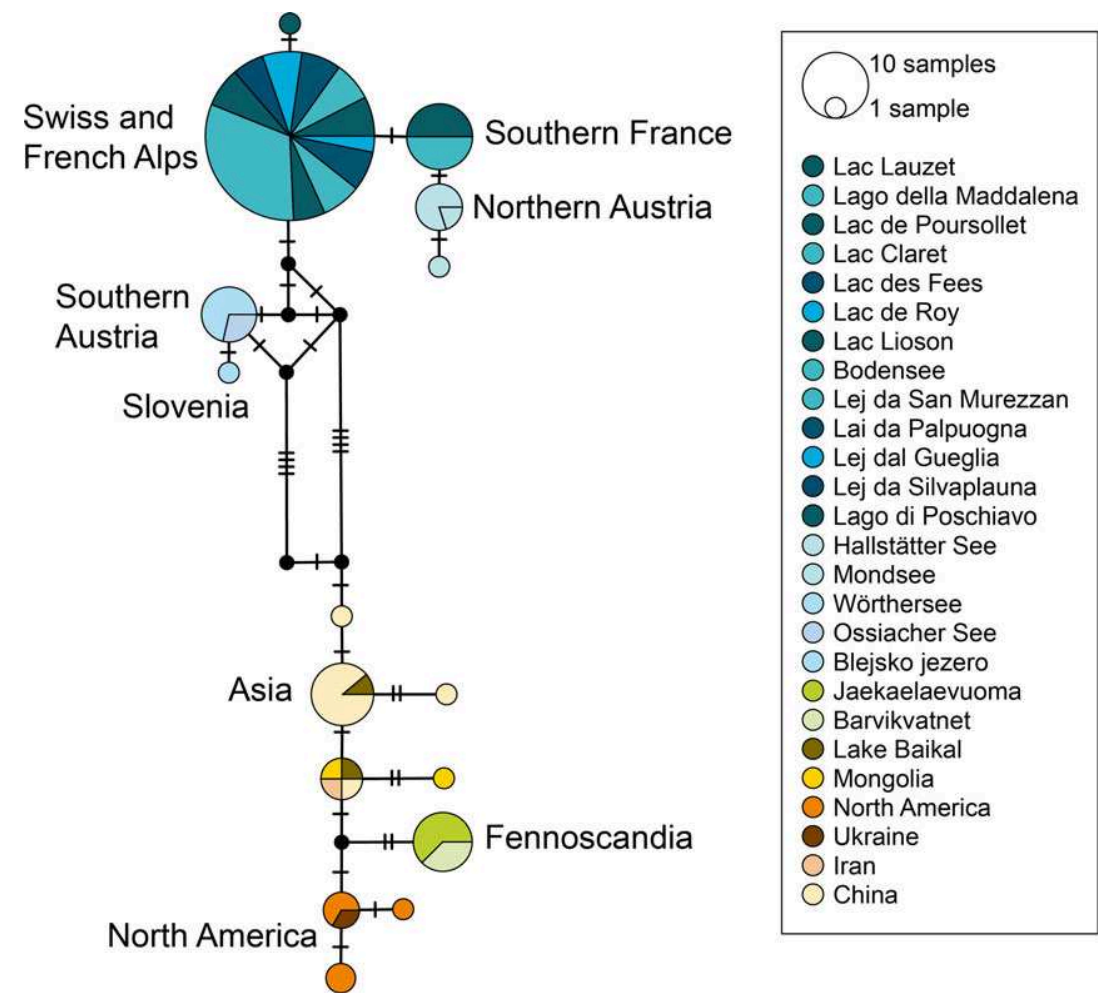

Figure 4. COI haplotype network. Haplotype network based on COI sequences calculated as a median joining network. Circles represent distinct haplotypes and different colours indicate sampling localities. 

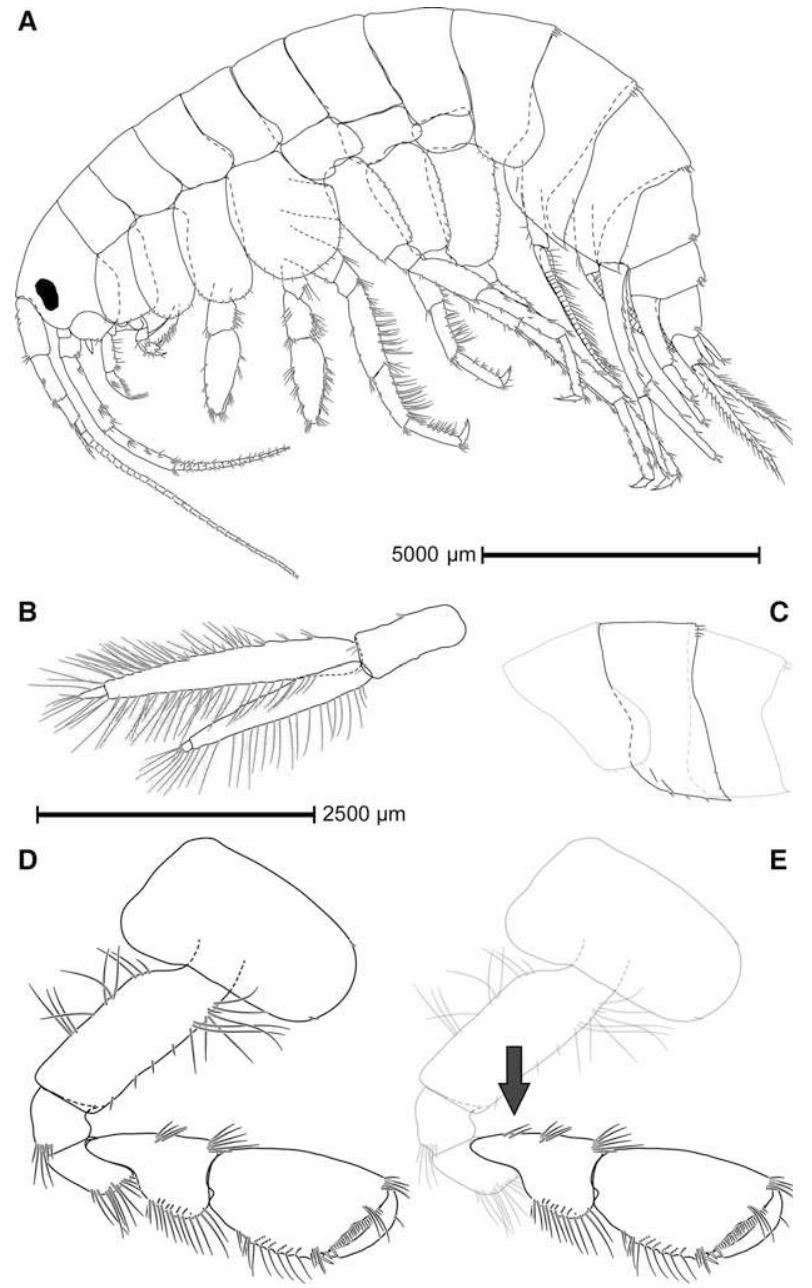

Figure 5. Habitus and detail drawings of Gammarus alpinus sp. nov. ( $\sigma^{\prime}, 21 \mathrm{~mm}$, Lej da San Murezzan, Switzerland). A, habitus; B, uropod 3 with long inner ramus; C, epimeral plate 2 with sharply pointed posteroinferior corner; D, gnathopod 2; E, derived and simplified gnathopod of G. lacustris indicating the second group of setae along anterior margin of carpopodite of gnathopod 2 to visualize the distinctive character between the sister species. Drawings by Vid Švara.

(voucher number GBIFCH00329236), along with four paratypes (20'; GBIFCH00329237 \& GBIFCH00329 238, 2\%; GBIFCH00329239 \& GBIFCH00329240) from the same location, collected by $R$. Alther, 27.VIII.2014. Ten additional paratypes $\left(5 \sigma^{\circ}, 5 \%\right)$ from Lej da Silvaplauna $\left(9^{\circ} 47026.97 \mathrm{E}, 46^{\circ} 27017.89 \mathrm{~N}\right)$, very close to the type locality, are deposited in our own collection at Eawag, Dübendorf. Additionally, DNA vouchers of analysed specimens are deposited in our own collection.
A

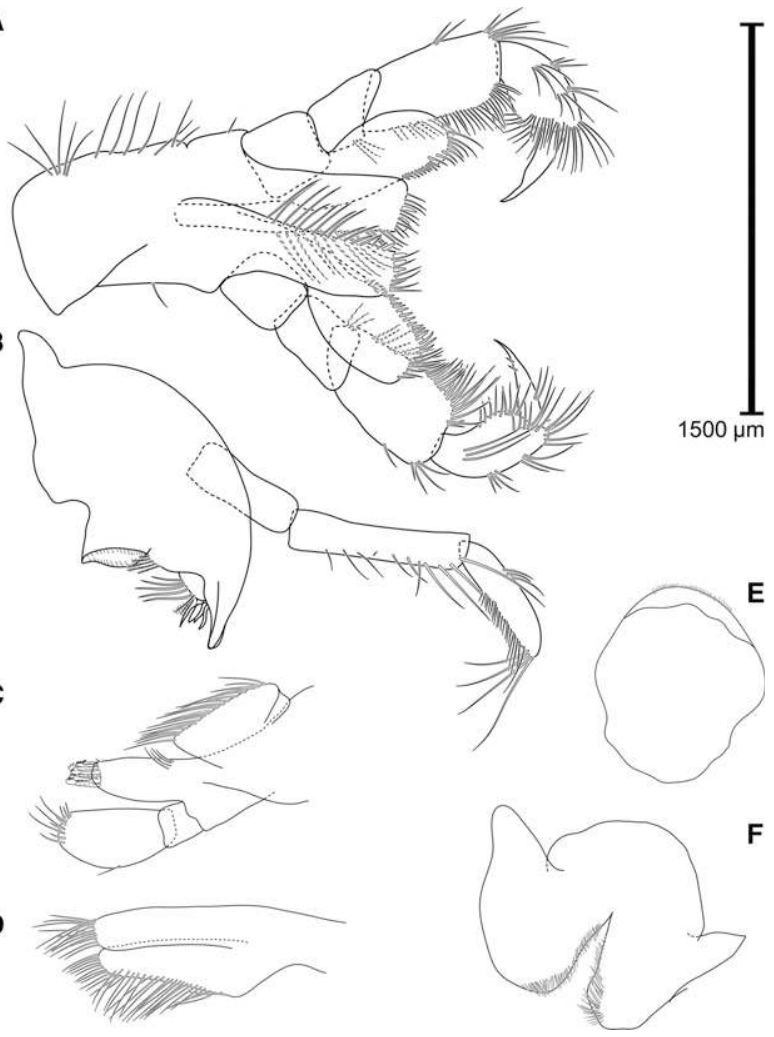

Figure 6. Mouthparts of Gammarus alpinus sp. nov. (o', $21 \mathrm{~mm}$, Lej da San Murezzan, Switzerland). A, left and right maxilliped; $\mathrm{B}$, mandibular palp, inner face; $\mathrm{C}$, maxilla 2; D, maxilla 1; E, labium/upper lip; F, labrum/ lower lip. Drawings by Vid Švara.

\section{Etymology}

The species epithet, alpinus, refers to its distribution throughout the European Alps, its probable endemic status there and its habitat preference for alpine lakes.

\section{Diagnosis}

Morphologically nearly identical to G. lacustris, it is a comparably large and robust species (Fig. 5A). Gammarus alpinus has only one clear group of two to six setae (and very rarely an isolated seta) along the anterior margin of the carpopodite of gnathopod 2 (Fig. 5D), while G. lacustris has two distinct groups that harbour five to eight setae in total (Fig. 5E).

\section{Description}

Body length: maximum length (TOT, see Supporting Information, Table S5) within 77 individuals from 18 localities (Supporting Information, Fig. S3) is $20 \mathrm{~mm}$ ( 9 , Lac de Roy, France). Adding the length of first antenna results in more than $32 \mathrm{~mm}$; maximum length of tip of rostrum to tip of third uropod is $25 \mathrm{~mm}$. Females slightly but significantly larger than 
males (based on a Welch two sample $t$-test, lengths with and without first antenna; mean length of ○ᄋ $=22.17$ and $15.00 \mathrm{~mm}$; mean length of $0^{\prime \prime} \sigma^{\prime \prime}=20.07$ and $13.68 \mathrm{~mm} ; P=0.043$ and 0.036 , respectively).

Head: eyes roundish or suboval, bean-like form widely found in the genus Gammarus; lateral cephalic lobe subrounded.

Antenna 1: seldom much longer than one-third of total body length (TOT + antenna 1), never half of it; setation relatively short; main and accessory flagella with 12-33 and 2-3 (up to 5) segments, respectively; length ratio of peduncular segments 1:2:3 = 1:0.83:0.53; peduncular segments 2 and 3 usually with one tuft of setae each.

Antenna 2: slightly longer than half of the first antenna; prominent and pointy tip of the glandular cone reaches peduncular segment 4; peduncular segments 4 and 5 armed with tufts of setae, usually arranged in three longitudinal rows; short and slender flagellum (4-16 segments, usually about 10) never with flag-like brush or swollen appearance; calceoli may be present but not prevalent and no apparent pattern for presence or absence has been found.

Mandibular palp: third segment (Fig. 6B) armed with one group of A-setae, one or two groups of Bsetae, 18-30 D-setae and 4-5 E-setae.

Metasome: segments 2 and 3 (Fig. 5C) can harbour some small setules along their posterior margins.

Urosome: even, without excavations or elevations.

Gnathopod 1: propodus piriform in both sexes; palmar margin with a single but strong medial spine; 3-12 angular spines along inferior margin of the propodus.

Gnathopod 2 (Fig. 5D): propodus with a more rectangular form; no prominent sexual dimorphism in shape; almost exclusively only a single group of setae present along anterior margin of carpopodite (exceptions in $2.6 \%$ or two out of 77 individuals), harbouring 2-5 setae (one specimen had 6).

Pereiopods: armature comparable to G. lacustris; no enlarged or prominent posteroinferior lobe in basis of pereiopods 5, 6 and 7; dactylus of P3-P7 distinctively more slender than in most other members of the the Gammarus pulex group (sensu Karaman \& Pinkster, 1977b).

Epimeral plates: posteroinferior corner of the first epimeral plate somewhat rounded, with a merely pointed and retracted edge, harbouring one seta; posteroinferior corner of second and third plate always sharply pointed (Fig. 5C); inferior margin of the epimeral plates harbours setae and often spines, with highly variable absolute number and ratio of spines to setae; often setae or spines on the lateral surface of the second epimeral plate; few short setae may be implanted along the posterior margin of the last two epimeral plates, spines were never recorded; number of spines and setae usually differs between left and right side of the individual.

Uropod 3: endopoditenearly reaches length of the first exopodal segment (Fig. 5B); second exopodite segment usually well developed; proportion of inner to outer ramus between three-quarters and 1; setae along inner and outer margins in both endo- and exopodite virtually always plumose.

Telson: lobes sparsely armed, usually with no more than one or two terminal spines and some setae, most of them usually at least as long as the spines; sometimes a subbasal spine can be found on the surface of the telson lobe in large individuals of both sexes.

Overall habitus: colour of live specimens is greyish to brown or rather white, depending on habitat in which they are found. Specimens can be covered with algae, especially around tufts of setae, depending on habitat.

Molecular diagnosis: affiliation to BIN BOLD: ACH6111 or BOLD:ADB3370 (http://www.boldsys tems.org) corresponds to belonging to Gammarus alpinus. In detail, within the aligned sequences of COI (658 bp, 5'-GACATTATATTTTGTTTTAG-...-CGTTTT AGCCGGAGCTATCA-3') we identified 14 SNPs, which are diagnostic for the alpine clade compared to the original G. lacustris (positions 103, 160, 163, 187, 211, 220, $274,337,343,347,370,448,523,553$ in $5^{\prime}-3^{\prime}$ reading direction). One SNP at site 337 even allows the distinction between all three clades. Nucleotide ' $\mathrm{T}$ ' indicates the initial G. lacustris, whereas ' $\mathrm{A}$ ' indicates the southeastern alpine clade and ' $\mathrm{C}$ ' indicates the north-eastern alpine clade.

\section{Variability}

The pattern of variability observed in G. alpinus reveals no significant differences among populations and the variability present is associated with postembryonic developmental changes as well as sexual differences.

\section{Distribution}

The species is restricted to the European Alps and has been recorded in Austria, France, Germany, Italy, Slovenia and Switzerland. Its possible distribution in the Balkans and Apennines (Pljakic, 1952; Pljakić, 1963; Iannilli \& Ruffo, 2002) remains to be confirmed.

\section{Remarks and affinities}

The morphological distinction from its sister species, G. lacustris, comes down to two stable quantitative characters and one qualitative character. One is the absence of a second group of setae (often as a single seta) along the anterior margin of the carpopodite of gnathopod 2 (present in G. alpinus). The second is that the anterior group of these setae harboured five 
or fewer setae (a single specimen was as exception), whereas in G. lacustris all studied specimens had at least five setae implanted (Fig. 5E) when summing up both setae groups (Supporting Information, Fig. S4). Additionally, the number of D-setae on the third segment of the mandibular palp seems to be slightly lower in G. alpinus, but without a clear cut-off allowing a reliable distinction. Whereas the structure of the epimeral plates is still a valid and strong discriminating character of the G. lacustris complex from other species of the Gammarus pulex-group, this character cannot be used in the discrimination of G. lacustris from $G$. alpinus. We thus suggest a distinction based on a barcoding approach, by extracting DNA from a pereiopod, applying the COI-barcoding protocol provided in this paper and aligning the resulting sequence to our published sequences on BOLD (BIN BOLD:ACH6111 or BOLD:ADB3370). Furthermore, we reason that individuals from France, Switzerland or southern Germany that would have been identified as G. lacustris until recently can be assigned to G. alpinus with a high degree of certainty.

\section{Ecology}

Gammarus alpinus has a bimodal elevational distribution (Fig. 7). It predominantly inhabits alpine lakes above $1500 \mathrm{~m}$ a.s.l. but also inhabits lowland lakes at around $300-500 \mathrm{~m}$ a.s.l. in close vicinity to the Alps. These two habitat types do not correspond to the molecular clades found in G. alpinus. The species has never been recorded in headwater streams. A few specimens were found downstream of Lake Constance as well as in small tributaries to Lake Constance close to the inlets (Altermatt et al., 2016). Whereas the first observation can be explained by passive drift, the findings in the inlets clearly suggest some ability to persist in slow running and small streams and creeks. Gammarus alpinus was often found to hide in conifer debris (R.A. \& F.A., pers. observa.). It can persist at very low temperatures close to $0{ }^{\circ} \mathrm{C}$ for a long time (findings in ice-sealed lakes).

\section{Zoological nomenclature}

In accordance with the ICZN Code of Nomenclature the new species name and status are registered in the Official Register of Zoological Nomenclature (ZooBank). ZooBank Life Science Identifier (LSID) for new species. http://zoobank.org/urn:lsid:zoobank.org: act:C1A6A35D-6F5E-4BD9-98D8-33AF8917C816.

\section{DISCUSSION}

\section{A NEW SPECIES AND ITS DISTRIBUTION}

We provide the first overview of the G. lacustris complex in the European Alps. The clear pattern of a highly divergent lineage compared to the circumboreal G. lacustris s.s. is surprising, given the wellknown occurrence in the Alps. We raise the alpine populations to species level based on consistent and stable morphological and molecular support, as well as by the clear geographical separation from its sister species. We consider that this separate status is stable and is strongly justified according to the concepts reviewed by De Queiroz (2007).

The newly described G. alpinus is probably endemic to the Alps, and does not overlap in its range with G. lacustris. Further analysis is needed to determine its distribution in Italy and Austria. Particular focus should be laid on the reported Apenninian populations of G. lacustris (Iannilli \& Ruffo, 2002). As they were described as genetically similar to alpine specimens, we suspect that they are representatives of G. alpinus as well. Sequences from work by Meyran \& Taberlet (1998) could not be directly included as their COI fragments were generated with different markers (COI a-H and COI-Gf) and the sequences do not match with the standard Folmer region. On a qualitative level, however, their findings of diverging lineages within the French populations are consistent with our overall findings. Whereas sequences from the northern French Alps match closely together with the Swiss sequences, sequences from the southern French Alps are slightly diverging and match better to sequences from the northern Austrian Alps.

\section{EVOLUTION AND BIOGEOGRAPHY OF THE G. LACUSTRIS SPECIES COMPLEX}

The previous view of $G$. lacustris as a homogeneous species is no longer justifiable, even though the truly circumboreal distribution still holds (Väinölä et al., 2008). Recent data from Asia Minor (Katouzian et al., 2016) and our data reveal a remarkable fragmentation in some southern and disjunct parts of the G. lacustris complex distribution. All fragmentation occurred in montane areas south of $48^{\circ} \mathrm{N}$, whereas populations in the north seem to be homogeneous. Previous findings on the worldwide molecular diversity of G. lacustris with a maximum value of $3.5 \%$ pairwise sequence divergence in $\mathrm{COI}(\mathrm{Hou}, \mathrm{Li} \& \mathrm{Li}$, 2009) are now contrasted with two examples of divergence from its sister species in separate regions [Irano-Anatolian/Caucasus (Katouzian et al., 2016) and European Alps (our study) biodiversity hotspots]. This new pattern indicates that geography and ecology of the species complex interact in the speciation process.

As observed in other alpine species, we initially assumed a divergence due to geographical separation during past glacial maxima with different refugia. 


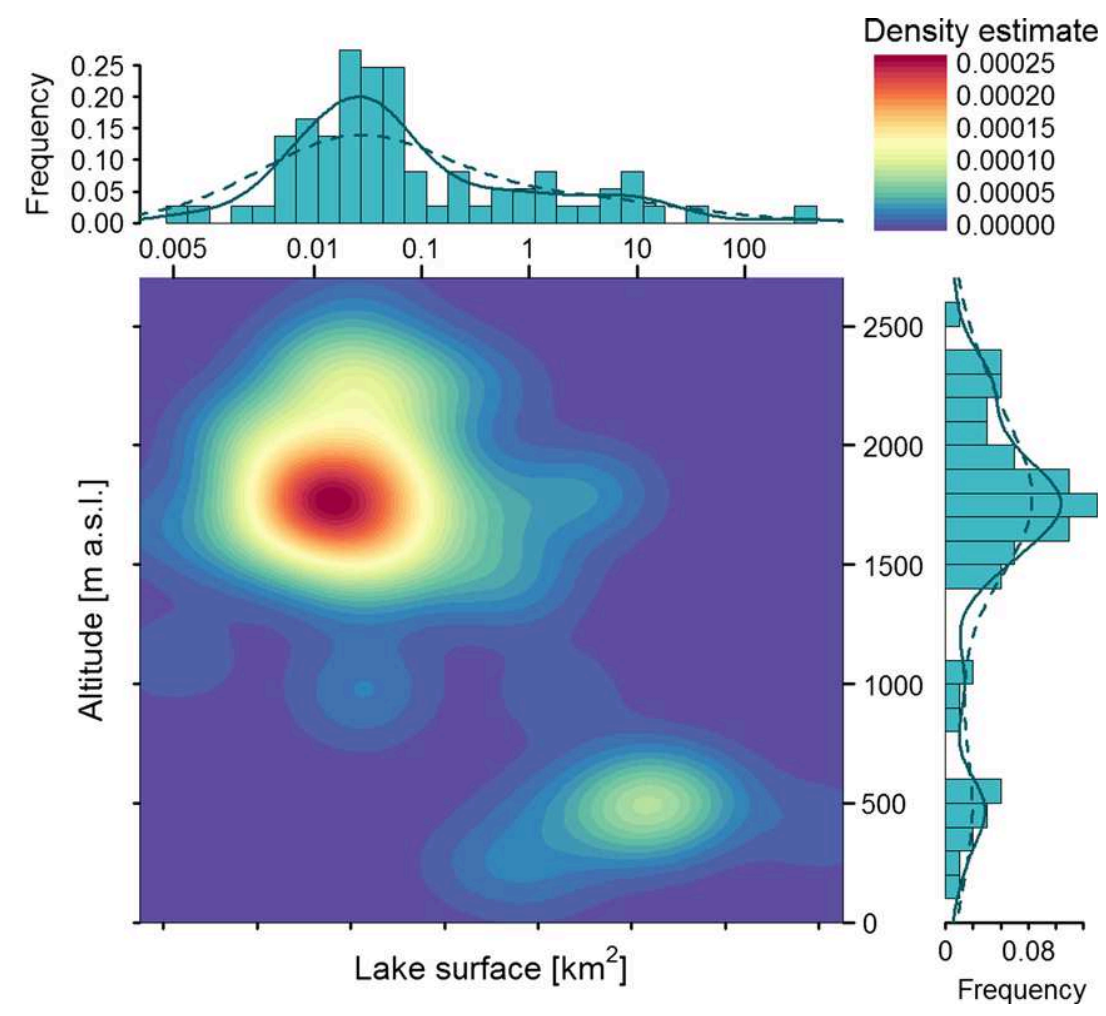

Figure 7. Habitat preferences of Gammarus alpinus sp. nov. Contour plot of the kernel density estimate of the altidudinal vs. lake surface distribution of all 78 lakes (out of 201 lakes) with reported populations of $G$. alpinus throughout the Alps. A slight bimodal pattern in both histograms highlights that the species can occur in large, pre-alpine lakes, such as Lake Constance, but is predominantly found in high-elevation, small alpine lakes. Kernel density estimates for the histograms are based on a smoothing bandwidth of $1 \times$ (solid line) and $2 \times$ (broken line) the SD of the kernel.

However, the estimated age of the split appears to have started before the beginning of the Quaternary in the late Miocene or early Pliocene. But as the split probably pre-dates the Pleistocene, we hypothesize that while glaciation of the Alps may not have started the speciation process, it is likely to have enhanced it, and the disconnection favoured the divergence into two separate species. Notably, during glacial maxima, G. alpinus populations were geographically much closer to Holarctic G. lacustris populations but they did not merge. This indicates that the two species might have been well differentiated by that time.

Gammarus alpinus occurs almost exclusively in areas draining into the Black Sea and the Mediterranean Sea (Fig. 1), indicating a southern refugium during glacial maxima. Moreover, this is supported by the absence of $G$. alpinus for most of the river Rhine drainage basin except around Lake Constance, which supports a split that could be dated back to a geological era when the predecessor of the alpine Rhine and Lake Constance were still draining into the Danube system (before 450000 years ago,
Berger et al., 2005; Keller, 2009; Heuberger, Büchi \& Naef, 2014). Even after warming in the Holocene, populations remaining in the colder Alps remained disconnected from the rest of the boreal populations due to the remoteness of the Alps from other occurrences of G. lacustris and warmer regions representing a barrier towards the north for cold-adapted G. alpinus.

Further studies in Italy and especially the Apennines could reveal additional information on the biogeographical history of G. alpinus in Central Europe. Certainly, the G. lacustris complex shows a completely different speciation pattern as detected in G. balcanicus and G. fossarum with their main speciation occurring 20 Mya in the Paratethys (Mamos et al., 2014, 2016; Copilaş-Ciocianu \& Petrusek, 2015). The current distribution and connectivity of habitats play a major role in species diversity and diversification. Whereas a patchy distribution might favour species divergence (Lefébure et al., 2007; Trontelj et al., 2009), a continuous distribution can have a homogenizing effect by dispersal and admixture of populations. Our lacustrine 
samples cover a comparable geographical range to the related species G. fossarum (e.g. Westram et al., 2011). However, we did not find greater diversity as compared to the better connected species such as G. fossarum (e.g. Weiss et al., 2014), but a quite similar level of morphological diversity and even lower genetic divergence within G.alpinus. This implies a temporal rather than a spatial explanation for the low diversity found within COI and $12 \mathrm{~S}$ sequences of the focal complex.

Clearly, more data are needed to explore the enigmatic evolutionary history and biogeography of this species complex. On the one hand, less conservative markers might bring insight into dispersal capacities of the circumboreal G. lacustris and perhaps help to identify the role of homogenizing factors such as transport by birds (Segerstråle, 1954) or even human-driven displacement, such as by fishermen or as a result of commercial bait trade. On the other hand, the taxonomic status of populations in mountain lakes of central Asia needs to be revised. Although sequences within GenBank included in our analysis from Tibet and the Himalayan region belong to G. lacustris, more cryptic species from Central Asia should not be ruled out.

\section{CONSERVATION IMPLICATIONS}

Invasive species are a major threat to aquatic species, especially to amphipods, which contain numerous invasive species themselves (Havel et al., 2015). Interestingly, we rarely found another species of amphipod co-occuring in the sampled alpine lakes, suggesting that invasive species are not yet a threat to high-elevation populations of $G$. alpinus. The situation of G. alpinus in the lower elevation lakes is different. Recent invasions into many of these lakes (Mürle, Becker \& Rey, 2003; Bącela-Spychalska et al., 2013) represent a threat to diversity (Dick \& Platvoet, 2000; Bollache et al., 2004). The most prominent example is the Pontocaspian amphipod Dikerogammarus villosus (Sowinsky, 1894), which has become an invasive species throughout Western Europe over the last few decades. It is already outcompeting species in larger lowland lakes, for example Lake Constance. Hence we suggest that high alpine lakes can be relatively undisturbed refugia for highly specialized freshwater species. However, once these ecosystems are disturbed and $G$. alpinus becomes locally extinct, recolonization may be strongly limited by the remoteness of the lakes. In summary, the impact of climate warming on cold-adapted $G$. alpinus per se, or in interaction with elevated pressure by invasive species, has unknown effects on this endemic gammarid and opens new questions regarding conservation and species persistence.

\section{CONCLUSION}

Combining molecular analysis with morphometric measurements we identified a novel species of a specialized and possibly endemic lacustrine Gammarus, distinct from its prominent sister species $G$. lacustris. We resolve the cryptic status and describe it as G. alpinus sp. nov., providing information on its molecular and morphological identification as well as on its distribution and ecology. The current distribution and its palaeogeographical explanation fit well with molecular data and suggest an early Pliocene diversification from its sister species $G$. lacustris. The species status is justified by its stable geographical separation. Its endemic status highlights the conservation importance of remote and high alpine lakes, which are threatened due to land-use change (especially eutrophication), climate warming and invasive species.

\section{ACKNOWLEDGEMENTS}

We thank L. Caduff, P. Ganesanandamoorthy, K. Kaelin, E. Mächler and B. Weigelt for help during the field and laboratory work. We thank R. Väinölä and $\mathrm{K}$. Kopp for providing specimens from Norway and Finland, and Austria, respectively. We also thank K. Bącela-Spychalska and M. Grabowski for providing information about their amphipod findings throughout Europe. We thank Vid Svara for the drawings of morphological characters and Teo Delić for advice with analyses in BEAST. We thank two anonymous reviewers for comments on previous versions of the manuscript. Funding is from Eawag Discretionary Funds, the Swiss National Science Foundation Grant PP00P3_150698 (to F.A.), the Swiss Federal Office for the Environment (BAFU, to F.A. and R.A.), the Slovenian Research Agency Program P1-0184 (to C.F.) and the Georges and Antoine Claraz Foundation (to R.A.). The data analysed in this paper were generated in collaboration with the Genetic Diversity Centre (GDC) ETH Zurich. The authors declare that they have no competing interests.

\section{REFERENCES}

Altermatt F, Alther R, Fišer C, Jokela J, Konec M, Küry D, Mächler E, Stucki P, Westram AM. 2014. Diversity and distribution of freshwater amphipod species in Switzerland (Crustacea: Amphipoda). PLoS ONE 9: e110328.

Altermatt F, Alther R, Mächler E. 2016. Spatial patterns of genetic diversity, community composition and occurrence of native and non-native amphipods in naturally replicated tributary streams. BMC Ecology 16: 23.

Bacela-Spychalska K, Grabowski M, Rewicz T, Konopacka A, Wattier RA. 2013. The 'killer shrimp' Dikerogammarus villosus (Crustacea, Ampahipoda) invading Alpine 
lakes: overland transport by recreational boats and scubadiving gear as potential entry vectors? Aquatic Conservation: Marine and Freshwater Ecosystems 23: 606-618.

Baele G, Lemey P, Bedford T, Rambaut A, Suchard MA, Alekseyenko AV. 2012. Improving the accuracy of demographic and molecular clock model comparison while accommodating phylogenetic uncertainty. Molecular Biology and Evolution 29: 2157-2167.

Bandelt HJ, Forster P, Röhl A. 1999. Median-joining networks for inferring intraspecific phylogenies. Molecular Biology and Evolution 16: 37-48.

Berger JP, Reichenbacher B, Becker D, Grimm M, Grimm K, Picot L, Storni A, Pirkenseer C, Derer C, Schaefer A. 2005. Paleogeography of the Upper Rhine Graben (URG) and the Swiss Molasse Basin (SMB) from Eocene to Pliocene. International Journal of Earth Sciences 94: $697-710$.

Bollache L, Devin S, Wattier RA, Chovet M, Beisel JN, Moreteau JC, Rigaud T. 2004. Rapid range extension of the Ponto-Caspian amphipod Dikerogammarus villosus in France: potential consequences. Archiv für Hydrobiologie 160: $57-66$.

Bouckaert R, Heled J, Kühnert D, Vaughan T, Wu CH, Xie D, Suchard MA, Rambaut A, Drummond AJ. 2014. BEAST 2: a software platform for Bayesian evolutionary analysis. PLoS Computational Biology 10:e1003537.

Brandley MC, Wang Y, Guo X, Montes De Oca AN, Fería-Ortíz M, Hikida T, Ota H. 2011. Accommodating heterogenous rates of evolution in molecular divergence dating methods: an example using intercontinental dispersal of plestiodon (Eumeces) lizards. Systematic Biology 60: 3-15.

Copilaş-Ciocianu D, Petrusek A. 2015. The south-western Carpathians as an ancient centre of diversity of freshwater gammarid amphipods: insights from the Gammarus fossarum species complex. Molecular Ecology 24: 3980-3992.

Darriba D, Taboada GL, Doallo R, Posada D. 2012. jModelTest 2: more models, new heuristics and parallel computing. Nature Methods 9: 772.

De Queiroz K. 2007. Species concepts and species delimitation. Systematic Biology 56: 879-886.

Dick JTA, Platvoet D. 2000. Invading predatory crustacean Dikerogammarus villosus eliminates both native and exotic species. Proceedings of the Royal Society B: Biological Sciences 267: 977-983.

Dirnböck T, Essl F, Rabitsch W. 2011. Disproportional risk for habitat loss of high-altitude endemic species under climate change. Global Change Biology 17: 990-996.

Drummond AJ, Bouckaert RR. 2015. Bayesian evolutionary analysis with BEAST. Cambridge, UK: Cambridge University Press.

Drummond AJ, Suchard MA. 2010. Bayesian random local clocks, or one rate to rule them all. BMC Biology 8: 114 .

Eggers TO, Martens A. 2001. Bestimmungsschlüssel der Süsswasser-Amphipoda (Crustacea) Deutschlands. Lauterbornia - Zeitschrift für Faunistik und Floristik des Süsswassers 42: 68.

Fišer Ž, Altermatt F, Zakšek V, Knapič T, Fišer C. 2015. Morphologically cryptic amphipod species are 'ecological clones' at regional but not at local scale: a case study of four Niphargus species. PLoS ONE 10: e0134384.

Folmer O, Black M, Hoeh W, Lutz R, Vrijenhoek R. 1994. DNA primers for amplification of mitochondrial cytochrome $\mathrm{c}$ oxidase subunit I from diverse metazoan invertebrates. Molecular Marine Biology and Biotechnology 3: 294-299.

Fontaine B, Bouchet P, Van Achterberg K, Alonso-Zarazaga MA, Araujo R, Asche M, Aspöck U, Audisio P, Aukema B, Bailly N, Balsamo M, Bank R a, Barnard P, Belfiore C, Bogdanowicz W, Bongers T, Boxshall G, Burckhardt D, Camicas JL, Chylarecki P, Crucitti P, Deharveng L, Dubois A, Enghoff H, Faubel A, Fochetti R, Gargominy O, Gibson D, Gibson R, Gómez López MS, Goujet D, Harvey MS, Heller KG, Van Helsdingen P, Hoch H, De Jong H, De Jong Y, Karsholt O, Los W, Lundqvist L, Magowski W, Manconi R, Martens J, Massard JA, Massard-Geimer G, Mcinnes SJ, Mendes LF, Mey E, Michelsen V, Minelli A, Nielsen C, Nieto Nafría JM, Van Nieukerken EJ, Noyes J, Pape T, Pohl H, De Prins W, Ramos M, Ricci C, Roselaar C, Rota E, Schmidt-Rhaesa A, Segers H, Strassen Zur R, Szeptycki A, Thibaud JM, Thomas A, Timm T, Van Tol J, Vervoort W, Willmann R. 2007. The European union's 2010 target: putting rare species in focus. Biological Conservation 139:167-185.

Foulquier A, Malard F, Lefébure T, Douady CJ, Gibert J. 2008. The imprint of Quaternary glaciers on the presentday distribution of the obligate groundwater amphipod Niphargus virei (Niphargidae). Journal of Biogeography 35: 552-564.

Galipaud M, Gauthey Z, Turlin J, Bollache L, Lagrue C. 2015. Mate choice and male-male competition among morphologically cryptic but genetically divergent amphipod lineages. Behavioral Ecology and Sociobiology 69: 1907-1916.

Gerhardt A. 2011. GamTox: a low-cost multimetric ecotoxicity test with Gammarus spp. for in and ex situ application. International Journal of Zoology 2011: 1-7.

Guindon S, Gascuel O. 2003. A simple, fast, and accurate algorithm to estimate large phylogenies by maximum likelihood. Systematic Biology 52: 696-704.

Havel JE, Kovalenko KE, Thomaz SM, Amalfitano S, Kats LB. 2015. Aquatic invasive species: challenges for the future. Hydrobiologia 750: 147-170.

Heuberger S, Büchi M, Naef H. 2014. Drainage system and landscape evolution of northern Switzerland since the Late Miocene. Wettingen, Switzerland: Nagra, Nationale Genossenschaft für die Lagerung radioaktiver Abfälle.

Hewitt GM. 1999. Post-glacial re-colonization of European biota. Biological Journal of the Linnean Society 68: 87-112.

Holsinger JR. 1976. The freshwater amphipod crustaceans (Gammaridae) of North America. Cincinnati, OH: U.S. Environmental Protection Agency.

Hou Z, Li S. 2010. Intraspecific or interspecific variation: delimitation of species boundaries within the genus Gammarus (Crustacea, Amphipoda, Gammaridae), with description of four new species. Zoological Journal of the Linnean Society 160: 215-253. 
Hou Z, Li Z, Li S. 2009. Identifying Chinese species of Gammarus (Crustacea: Amphipoda) using DNA barcoding. Current Zoology 55: 158-164.

Hou Z, Sket B. 2016. A review of Gammaridae (Crustacea: Amphipoda): the family extent, its evolutionary history, and taxonomic redefinition of genera. Zoological Journal of the Linnean Society 176: 323-348.

Hou Z, Sket B, Fišer C, Li S. 2011. Eocene habitat shift from saline to freshwater promoted Tethyan amphipod diversification. Proceedings of the National Academy of Sciences of the United States of America 108: 14533-14538.

Hou Z, Sket B, Li S. 2014. Phylogenetic analyses of Gammaridae crustacean reveal different diversification patterns among sister lineages in the Tethyan region. Cladistics 30: $352-365$.

Hynes HBN. 1957. Note sur les Gammarus de Suisse. Revue Suisse de Zoologie 64: 215-217.

Iannilli V, Ruffo S. 2002. Apennine and Sardinian species of Gammarus, with the description of Gammarus elvirae n. sp. (Crustacea Amphipoda, Gammaridae). Bollettino dell'Accademia Gioenia di Scienze Naturali 35: 519-532.

Jacobsen D, Milner AM, Brown LE, Dangles O. 2012. Biodiversity under threat in glacier-fed river systems. Nature Climate Change 2: 1-4.

Josse J, Husson F. 2012. Handling missing values in exploratory multivariate data analysis methods. Journal de la Société Française de Statistique 153: 79-99.

Karaman GS. 1993. Crustacea: amphipoda di acqua dolce. Bologna: Edizioni Calderini Bologna.

Karaman GS, Pinkster S. 1977a. Freshwater Gammarus species from Europe, North-Africa and adjacent regions of Asia (Crustacea-Amphipoda). II. Gammarus-roeseli-group and related species. Bijdragen tot de Dierkunde 47: 165196.

Karaman GS, Pinkster S. 1977b. Freshwater Gammarus species from Europe, North Africa and adjacent regions of Asia (Crustacea-Amphipoda): part I. Gammarus pulexgroup and related species. Bijdragen tot de Dierkunde 47: $1-97$.

Katouzian AR, Sari A, Macher JN, Weiss M, Saboori A, Leese F, Weigand AM. 2016. Drastic underestimation of amphipod biodiversity in the endangered Irano-Anatolian and Caucasus biodiversity hotspots. Scientific Reports 6: 22507.

Keller O. 2009. Als der Alpenrhein sich von der Donau zum Oberrhein wandte. Schriften des Vereins für Geschichte des Bodensees und seiner Umgebung 127: 193-208.

Kimura M. 1980. A simple method for estimating evolutionary rates of base substitutions through comparative studies of nucleotide sequences. Journal of Molecular Evolution 16: 111-120.

Lagrue C, Wattier R, Galipaud M, Gauthey Z, Rullmann JP, Dubreuil C, Rigaud T, Bollache L. 2014. Confrontation of cryptic diversity and mate discrimination within Gammarus pulex and Gammarus fossarum species complexes. Freshwater Biology 59: 2555-2570.

Larkin MA, Blackshields G, Brown NP, Chenna R, McGettigan PA, McWilliam H, Valentin F, Wallace IM,
Wilm A, Lopez R, Thompson JD, Gibson TJ, Higgins DG. 2007. Clustal $\mathrm{W}$ and Clustal $\mathrm{X}$ version 2.0. Bioinformatics 23: 2947-2948.

Lefébure T, Douady CJ, Malard F, Gibert J. 2007. Testing dispersal and cryptic diversity in a widely distributed groundwater amphipod (Niphargus rhenorhodanensis). Molecular Phylogenetics and Evolution 42: 676-686.

Leigh JW, Bryant D. 2015. PopART: Full-Feature Software for Haplotype Network Construction. Methods in Ecology and Evolution 6: 1110-1116.

MacDonald KS III, Yampolsky L, Duffy JE. 2005. Molecular and morphological evolution of the amphipod radiation of Lake Baikal. Molecular Phylogenetics and Evolution 35: 323-343.

Mamos T, Wattier RA, Majda A, Sket B, Grabowski M. 2014. Morphological vs. molecular delineation of taxa across montane regions in Europe: the case study of Gammarus balcanicus Schäferna, (Crustacea: Amphipoda). Journal of Zoological Systematics and Evolutionary Research 52: 237-248.

Mamos T, Wattier R, Burzyński A, Grabowski M. 2016. The legacy of a vanished sea: a high level of diversification within a European freshwater amphipod species complex driven by $15 \mathrm{My}$ of Paratethys regression. Molecular Ecology 25: 795-810.

Meyran JC, Taberlet P. 1998. Mitochondrial DNA polymorphism among alpine populations of Gammarus lacustris (Crustacea, Amphipoda). Freshwater Biology 39: 259-265.

Müller JC. 2000. Mitochondrial DNA variation and the evolutionary history of cryptic Gammarus fossarum types. Molecular Phylogenetics and Evolution 15: 260-268.

Müller JC, Partsch E, Link A. 2000. Differentiation in morphology and habitat partitioning of genetically characterized Gammarus fossarum forms (Amphipoda) across a contact zone. Biological Journal of the Linnean Society 69: 41-53.

Mürle U, Becker A, Rey P. 2003. Ein neuer Flohkrebs im Bodensee: Dikerogammarus villosus (Grosser Höckerflohkrebs). http://www.bodensee-ufer.de.

Nagy L, Grabherr G, Körner C, Thompson DBA. 2012. Alpine Biodiversity in Europe. Berlin: Springer Science \& Business Media.

Pljakic MA. 1952. A contribution to the study of the distribution of Gammarus (Rivulogammarus) pulex fossarum in Serbia. Arhiv Bioloških Nauka 4: 81-88.

Pljakić MA. 1963. Verbreitung des Gammarus (Riv.) lacus tris Sars in den Gebirgseen Jugoslawiens. Arhiv Bioloških Nauka 15: 111-121.

$\mathrm{R}$ Core Team. 2015. R: A language and environment for statistical computing.

Rasband WS. 2014. ImageJ.

Revenga C, Campbell I, Abell R, de Villiers P, Bryer M. 2005. Prospects for monitoring freshwater ecosystems towards the 2010 targets. Philosophical transactions of the Royal Society of London Series B, Biological sciences 360: 397-413.

Rogers DC, Covich AP, Thorp JH. 2010. Introduction to the subphylum Crustacea. In: Thorp JH, Covich AP, eds. Ecology and classification of North American freshwater invertebrates. San Diego: Academic Press (Elsevier), 695-724. 
Schellenberg A. 1934. Der Gammarus des deutschen Süsswassers. Zoologischer Anzeiger 108: 209-217.

Segerstråle SG. 1954. The freshwater Amphipoda, Gammarus pulex (L.) and Gammarus lacustris G. O. Sars, in Denmark and Fennoscandia - a contribution to the lateand post-glacial immigration history of the aquatic fauna of Northern Europe. Societas Scientiarum Fennica Commentationes Biologicae 15: 1-91.

Stewart JR, Lister AM, Barnes I, Dalén L. 2010. Refugia revisited: individualistic responses of species in space and time. Proceedings Biological sciences/The Royal Society 277: $661-671$.

Stöver BC, Müller KF. 2010. TreeGraph 2: combining and visualizing evidence from different phylogenetic analyses. BMC Bioinformatics 11: 7.

Stucki P. 2010. Methoden zur Untersuchung und Beurteilung der Fliessgewässer. Makrozoobenthos Stufe F. Umwelt-Vollzug 1026: 61.

Sworobowicz L, Grabowski M, Mamos T, Burzyński A, Kilikowska A, Sell J, Wysocka A. 2015. Revisiting the phylogeography of Asellus aquaticus in Europe: insights into cryptic diversity and spatiotemporal diversification. Freshwater Biology 60: 1824-1840.

Tachet H, Richoux P, Bournaud M, Usseglio-Polatera P. 2010. Invertébrés d'eau douce. Systématique, biologie, écologie. Paris: CNRS Éditions.

Tamura K, Stecher G, Peterson D, Filipski A, Kumar S. 2013. MEGA6: molecular evolutionary genetics analysis version 6.0. Molecular Biology and Evolution 30: 2725-2729.

Trontelj P, Utevsky SY. 2005. Celebrity with a neglected taxonomy: molecular systematics of the medicinal leech (genus Hirudo). Molecular Phylogenetics and Evolution 34: 616-624.

Trontelj P, Douady CJ, Fišer C, Gibert J, Gorički Š, Lefébure T, Sket B, Zakšek V. 2009. A molecular test for cryptic diversity in ground water: how large are the ranges of macro-stygobionts? Freshwater Biology 54: 727-744.

Vainio JK, Väinölä R. 2003. Refugial races and postglacial colonization history of the freshwater amphipod Gammarus lacustris in Northern Europe. Biological Journal of the Linnean Society 79: 523-542.

Väinölä R, Witt JDS, Grabowski M, Bradbury JH, Jazdzewski K, Sket B. 2008. Global diversity of amphipods (Amphipoda; Crustacea) in freshwater. Hydrobiologia 595: 241-255.

Venables WN, Ripley BD. 2002. MASS: modern applied statistics with $S$. New York: Springer.

Vornatscher J. 1965. Catalogus Faunae Austriae. Ein systematisches Verzeichnis aller auf österreichischem Gebiet festgestellten Tierarten, Teil VIII f: Amphipoda. Wien: Kommission für Interdisziplinäre Ökologische Studien der Österreichischen Akademie der Wissenschaften, Springer-Verlag.

Vörösmarty CJ, Mcintyre PB, Gessner MO, Dudgeon D, Prusevich A, Green P, Glidden S, Bunn SE, Sullivan CA, Reidy Liermann C, Davies PM. 2010. Global threats to human water security and river biodiversity. Nature 467: $555-561$.

Weiss M, Macher JN, Seefeldt MA, Leese F. 2014. Molecular evidence for further overlooked species within the Gammarus fossarum complex (Crustacea: Amphipoda). Hydrobiologia 721: 165-184.

Westram AM, Jokela J, Baumgartner C, Keller I. 2011. Spatial distribution of cryptic species diversity in european freshwater amphipods (Gammarus fossarum) as revealed by pyrosequencing. PLoS ONE 6: e23879.

Wiens JJ. 2015. Faster diversification on land than sea helps explain global biodiversity patterns among habitats and animal phyla. Ecology Letters 18: 1234-1241.

Wiens JJ, Moen DS. 2008. Missing data and the accuracy of Bayesian phylogenetics. Journal of Systematics and Evolution 46: 307-314.

Williams HC, Ormerod SJ, Bruford MW. 2006. Molecular systematics and phylogeography of the cryptic species complex Baetis rhodani (Ephemeroptera, Baetidae). Molecular Phylogenetics and Evolution 40: 370-382.

Zhang J, Kapli P, Pavlidis P, Stamatakis A. 2013. A general species delimitation method with applications to phylogenetic placements. Bioinformatics 29: 2869-2876.

\section{SUPPORTING INFORMATION}

Additional supporting information may be found online in the supporting information tab for this article:

Figure S1. ML-inferred phylogenetic tree of Gammarids found in the Alps.

Figure S2. Pairwise differences of $12 \mathrm{~S}$ sequences.

Figure S3. Sampled lakes and origin of specimens for molecular analysis.

Figure S4. Morphological difference in gnathopod 2 between $\boldsymbol{G}$. alpinus sp. nov. and G. lacustris.

Table S1. Publications screened for information on the occurrence/records of G. lacustris in alpine and prealpine freshwater habitats.

Table S2. Sampled lakes (102 total).

Table S3. BOLD BINs and GenBank accession numbers of newly generated COI and $12 \mathrm{~S}$ sequences.

Table S4. GenBank accession numbers of available and included COI sequences [accessed 12 January 2015].

Table S5. Measured morphological characters for morphometric analysis. 